(1)

CrossMark

\title{
Minimising the environmental impact of inhaled therapies
}

\author{
To the Editor:
}

We read with interest the recent editorial by KeELEY et al. [1] on the timely topic of changing pressurised metered dose inhalers (pMDIs) to dry powder inhalers (DPIs) due to the much higher carbon footprint of pMDIs [2]. We agree with the authors that global warming cannot be tackled only by focusing on inhaler devices, but as long as we can provide safe and effective treatment to our patients, we cannot overlook environmental facts either. We feel that KEELEY et al. [1] gave an unjustified negative impression on the performance of DPIs. They imply that DPIs are more expensive than pMDIs, that switching from pMDI to DPI leads to poorer asthma control, and that patients using DPIs should have a pMDI+spacer rescue pack since DPIs cannot be relied on as rescue medication. However, we feel that these misleading claims are based on wrong interpretations of the publications they cite, or on opinions without any supporting data. Since in many countries, like in Finland and Sweden, good control of asthma and COPD is achieved at a national level $[3,4]$ while the majority of patients using inhaled therapies are treated with DPIs, $(56 \%$ in Finland and $71 \%$ in Sweden, according to IQVIA standard units volume data for 2019), we think it is worth correcting these wrong impressions.

The authors write that "In many cases, pMDIs are significantly less costly than DPIs and a shift towards greater use of DPIs could cause a substantial increase in healthcare drug costs" and they cite SAKAAN et al. [5]. However, the study they cite was about waste of drug doses in patients hospitalised for asthma or COPD and dispensed new inhalers in hospital, not about costs of maintenance treatment at home. The study made no comparison of costs between DPI and PMDI, and there is no statement in the publication that DPI would be more expensive than pMDI. On the contrary, there is a recent study showing that switching maintenance treatment from pMDI to DPI would not only be environmentally friendly but has also potential to reduce costs [6].

KEELEY et al. [1] lead the reader to understand that in Finland the government enforced patients to be switched from pMDIs to DPIs leading to impaired disease control. In Finland, there has not been such a governmental enforcement. Although a majority (56\%) of patients are treated with DPIs (IQVIA data, 2019), the outcomes of asthma treatment on national level have been very good [3]. The study they cite was conducted in Iceland [7], not Finland, and the study was not at all about inhaler types but about drug classes: in Iceland decrease in use of inhaled corticosteroid (ICS) and ICS plus long-acting $\beta$-agonist due to a change in reimbursement policy led to increased use of short-acting $\beta$-agonist and oral corticosteroids, and to increased rate of hospitalisations. In this study, nothing suggested that the outcome was in any way related to inhaler type, but it was an expected result of decreased maintenance treatment. On the contrary to what KeELEY et al. [1] imply, there are several real-life studies showing that many patients can have their inhaler safely switched $[8,9]$, but we agree that patient education is important to remember. In addition, the vast majority of patients are able to achieve adequate inspiratory flow with DPIs [10], contrary to what is claimed by the authors based on only one reference from 1992. The authors also suggest that patients treated with DPIs should have a rescue pack of reliever pMDI+spacer at home and they cite their own previous letter stating this same opinion without any data supporting it [11].

We agree that DPIs have not been shown to be suitable for treating life-threatening attacks or to be used in emergency rooms. However, as the authors rightly state, asthma mortality rate is much lower in many countries using a lot of DPIs as compared to higher mortality rates in UK where DPIs are used less (11\%) (IQVIA data 2019). Thus, there are no studies showing that patients using DPI relievers are in any greater risk than those relying on pMDI relievers, and real-life asthma outcome on national level is actually better in many countries with higher use of DPIs.

@ERSpublications

Environmental burden of inhaled therapies needs to be considered, as long as treatment efficacy and safety are secured https://bit.ly/3bRSl07

Cite this article as: Lehtimäki L, Björnsdóttir U, Janson C, et al. Minimising the environmental impact of inhaled therapies. Eur Respir J 2020; 55: 2000721 [https://doi.org/10.1183/13993003.00721-2020]. 
Lastly, the editorial includes a table, "Reducing the environmental impact of inhalers in respiratory care". This implies that the authors cover all inhalers, although it almost solely focuses on pMDIs. A more suitable title would be "Reducing the environmental impact of pMDIs in respiratory care" and to the "What to do" column "Consider switching to a suitable DPI" would be a justified addition in many of the points. We acknowledge that not all patients, especially young children, are able to use a DPI, but there is significant body of evidence supporting their use in the vast majority of those with asthma.

Lauri Lehtimäki ${ }^{1,2}$, Unnur Björnsdóttir ${ }^{3}$, Christer Janson $\oplus^{4}$ and Tari Haahtela ${ }^{5}$

${ }^{1}$ Allergy Centre, Tampere University Hospital, Tampere, Finland. ${ }^{2}$ Faculty of Medicine and Health Technology, Tampere University, Tampere, Finland. ${ }^{3}$ Dept of Respiratory Medicine, Landspitali University Hospital, Reykjavik, Iceland. ${ }^{4}$ Dept of Medical Sciences, Respiratory, Allergy and Sleep Research Uppsala University, Uppsala, Sweden. ${ }^{5}$ Skin and Allergy Hospital, Helsinki University Hospital, University of Helsinki, Helsinki, Finland.

Correspondence: Lauri Lehtimäki, Tampere University Hospital, Allergy Centre, PO Box 2000, 33521 Tampere, Finland. E-mail: lauri.lehtimaki@tuni.fi

Received: 17 March 2020 | Accepted: 29 March 2020

Conflict of interest: L. Lehtimäki reports personal fees from AstraZeneca, Boehringer Ingelheim, Chiesi, Circassia, GSK, Novartis, Mundipharma, Orion Pharma, Sanofi and Teva, outside the submitted work. U. Björnsdóttir reports personal fees from AstraZeneca, Novartis and Sanofi, outside the submitted work. C. Janson reports personal fees for educational activities from AstraZeneca, Chiesi, Boehringer Ingelheim, GlaxoSmithKline, Novartis and Teva, outside the submitted work. T. Haahtela reports personal fees for lectures from GSK, Mundipharma and Orion Pharma, during the conduct of the study.

\section{References}

1 Keeley D, Scullion JE, Usmani OS. Minimising the environmental impact of inhaled therapies: problems with policy on low carbon inhalers. Eur Respir J 2020; 55 : 2000048.

2 Janson C, Henderson R, Löfdahl M, et al. Carbon footprint impact of the choice of inhalers for asthma and COPD. Thorax 2020; 75: 82-84.

3 Haahtela T, Herse F, Karjalainen J, et al. The Finnish experience to save asthma costs by improving care in 19872013. J Allergy Clin Immunol 2017; 139: 408-414.

4 Gibson GJ, Loddenkemper R, Sibille Y, et al., eds. Adult asthma. In: European Lung White Book. Sheffield, European Respiratory Society, 2013.

5 Sakaan S, Ulrich D, Luo J, et al. Inhaler use in hospitalized patients with chronic obstructive pulmonary disease or asthma: assessment of wasted doses. Hosp Pharm 2015; 50: 386-390.

6 Wilkinson AJK, Braggins R, Steinbach I, et al. Costs of switching to low global warming potential inhalers. An economic and carbon footprint analysis of NHS prescription data in England. BMJ Open 2019; 9: e028763.

7 Björnsdóttir US, Sigurðardóttir ST, Jonsson JS, et al. Impact of changes to reimbursement of fixed combinations of inhaled corticosteroids and long-acting $\beta_{2}$-agonists in obstructive lung diseases: a population-based, observational study. Int J Clin Pract 2014; 68: 812-819.

8 Gálffy G, Szilasi M, Tamási L. Effectiveness and patient satisfaction with budesonide/formoterol Easyhaler among patients with asthma or COPD switching from previous treatment: a real-world study of patient-reported outcomes. Pulm Ther 2019; 5: 165-177.

9 Bloom CI, Douglas I, Olney J, et al. Cost saving of switching to equivalent inhalers and its effect on health outcomes. Thorax 2019; 74: 1078-1086.

10 Levy ML, Carroll W, Izquierdo Alonso JL, et al. Understanding dry powder inhalers: key technical and patient preference attributes. Adv Ther 2019; 36: 2547-2557.

11 Keeley D, Partridge MR. Emergency MDI and spacer packs for asthma and COPD. Lancet Respir Med 2019; 7: $380-382$.

\section{Minimising the environmental impact of inhaled therapies: problems with policy on low carbon inhalers}

From the authors:

We thank L. Lehtimäki and colleagues for their letter, and acknowledge and apologise for the error they identify relating to the country of the study [1]. All respiratory inhaled treatments are a combination of 
the drug and device, and we cited the Icelandic study to illustrate that an enforced switch of treatment by the government, here to low-cost alternatives, led to poorer clinical outcomes [1]. In this context, the mandated recommendations of the UK government for environmental reasons, give cause for concern. Our editorial stresses the necessity for patient engagement and choice, as well as clinical efficacy, to be considered in all steps of inhaler prescribing.

Non-consensual switches may result in discontent and lack of confidence amongst patients, and it has been suggested that patients with stable respiratory disease remain on their current inhaler device [2]. Prescribers must therefore take account of their patient's preference, and data show patients prefer an aqueous-based aerosol device rather than a dry-powder aerosol in comparative inhaler device studies with the same therapeutic drug [3, 4]. Efficacy data from real-world studies have suggested that the dry-powder inhaler (DPI) device with the same drug components gives poorer patient outcomes in asthma and COPD, compared to a pressurised metered dose inhaler (pMDI) $[5,6]$. One inhaler does not fit all, so prescribers should choose a device that is tailored to patients' individual and specific needs.

A UK prescribing cost analysis model indeed suggested the possibility of cost savings with increased use of DPIs, but this was dependent on prescribers using the lowest cost alternatives when switching, with significant cost increases should that not be the case [7]. Globally, continued access to low-cost inhalers will be vital for prescribers in low-income countries. We also highlight the need to carefully interrogate the data used in the models that underlie proposals for change; for example, recent work on the carbon footprint of pMDIs show this to be lower than that quoted in official documents [8]. The idea of combining pMDI with spacer as an emergency pack is evidence-based, since the effectiveness of the components of this therapeutic approach in exacerbations of asthma has been shown [9]. This could usefully form part of the self-management options for patients with asthma, regardless of the inhaler type used for routine therapy.

We acknowledge that our table should have included consideration of a low global warming potential device as one element in a carefully controlled approach to reducing the environmental impact of respiratory treatments. However, interpreting this as a switch to the DPI device class is wrong. When a change in treatment is being considered, healthcare professionals should consider "low global warming potential" (GWP) devices that include low-GWP pMDIs, DPIs and soft mist inhalers. Indeed, within 5 years, we will have clinically available pMDIs with potentially lower GWP than current DPIs [8]. It is vital, both in the UK context and internationally, that patients with asthma and COPD who need pMDIs retain access to them.

In the UK, as elsewhere, healthcare systems are currently operating under the massive additional stress of the coronavirus disease 2019 pandemic. Any change in the pattern of inhaler use should be deferred until a more normal service can be resumed, and none of our respiratory patients should be forced into switching inhalers. We must redouble our efforts to improve the education of health care professionals and patients in the use of inhaler devices. For sure, the greenest inhaler is an appropriately prescribed device, that the patient has been properly taught and assessed how to use, is happy with and most important of all, gives them clinical benefit [10].

@ERSpublications

The greenest inhaler is an appropriately prescribed device, that the patient has been properly taught and assessed how to use, is happy with and most important of all, gives them clinical benefit https:// bit.ly/2VKicQW

Cite this article as: Keeley D, Scullion JE, Usmani OS. Minimising the environmental impact of inhaled therapies: problems with policy on low carbon inhalers. Eur Respir J 2020; 55: 2001122 [https://doi.org/ 10.1183/13993003.01122-2020].

Duncan Keeley ${ }^{1}$, Jane E. Scullion $\oplus^{2}$ and Omar S. Usmani ${ }^{3}$

${ }^{1}$ Thame, UK. ${ }^{2}$ University Hospitals of Leicester NHS Trust, Leicester, UK. ${ }^{3}$ National Heart and Lung Institute, Imperial College London, London, UK.

Correspondence: Omar S. Usmani, Imperial College London and Royal Brompton Hospital, National Heart and Lung Institute (NHLI), Airways Disease Section, Dovehouse Street, London SW3 6LY, UK. E-mail: o.usmani@imperial.ac.uk

Received: 11 April 2020 | Accepted: 11 April 2020

Conflict of interest: D. Keeley has nothing to disclose. J.E. Scullion reports personal fees from AstraZeneca, Boehringer Ingelheim, Chiesi, Napp, Mundipharma, Sandoz, Teva, Roche, Guidelines for nurses, MA healthcare, Orion and MIMS, outside the submitted work. O.S. Usmani reports grants and personal fees from AstraZeneca, Boehringer Ingelheim and Chiesi, grants from GlaxoSmithKline, Prosonix and Edmond Pharma, personal fees from Aerocrine, Napp, Mundipharma, Sandoz, Takeda, Zentiva, Cipla and Pearl Therapeutics, outside the submitted work. 


\section{References}

1 Björnsdóttir US, Sigurðardóttir ST, Jonsson JS, et al. Impact of changes to reimbursement of fixed combinations of inhaled corticosteroids and long-acting $\beta_{2}$-agonists in obstructive lung diseases: a population-based, observational study. Int J Clin Pract 2014; 68: 812-819.

2 Bjermer L. The importance of continuity in inhaler device choice for asthma and chronic obstructive pulmonary disease. Respiration 2014; 88: 346-352.

3 Dekhuijzen PN, Lavorini F, Usmani OS. Patients' perspectives and preferences in the choice of inhalers: the case for Respimat or HandiHaler. Patient Prefer Adherence 2016; 10: 1561-1572.

4 Muraki M, Gose K, Hanada S, et al. Which inhaled corticosteroid and long-acting $\beta$-agonist combination is better in patients with moderate-to-severe asthma, a dry powder inhaler or a pressurized metered-dose inhaler? Drug Deliv 2017; 24: 1395-1400.

5 Price D, Roche N, Christian Virchow J, et al. Device type and real-world effectiveness of asthma combination therapy: an observational study. Respir Med 2011; 105: 1457-1466.

6 Jones R, Martin J, Thomas V, et al. The comparative effectiveness of initiating fluticasone/salmeterol combination therapy via pMDI versus DPI in reducing exacerbations and treatment escalation in COPD: a UK database study. Int J Chron Obstruct Pulmon Dis 2017; 12: 2445-2454.

7 Wilkinson AJK, Braggins R, Steinbach I, et al. Costs of switching to low global warming potential inhalers. An economic and carbon footprint analysis of NHS prescription data in England. BMJ Open 2019; 9: e028763.

8 Panigone S, Sandri F, Ferri R, et al. Environmental impact of inhalers for respiratory diseases: decreasing the carbon footprint while preserving patient-tailored treatment. BMJ Open Respir Res 2020; 7: e000571.

9 Keeley D, Partridge MR. Emergency MDI and spacer packs for asthma and COPD. Lancet Respir Med 2019; 7: 380-382.

10 Lavorini F, Usmani OS. Correct inhalation technique is critical in achieving good asthma control. Prim Care Respir J 2013; 22: 385-386. 